\title{
Radiographic Length
}

National Cancer Institute

\section{Source}

National Cancer Institute. Radiographic Length. NCI Thesaurus. Code C158769.

The longest perpendicular diameter of a tumor from the results of an imaging modality. 